\title{
Comparative Study of Prostatic Diseases Bph and Prostatic Cancer by Estimating Serum Pap and Total Psa Levels
}

\author{
N. Sridevi M.D ${ }^{1}$ \\ ${ }^{1}$ Associate Professor, Department of Biochemistry, Guntur Medical College, Guntur.
}

\begin{abstract}
Objective: To compare prostatic diseases like BPH and Prostatic cancer by estimating the levels of serum Prostatic Acid phosphatase (PAP) and total PSA levels. PSA is an extremely useful tumour marker in prostatic diseases. In normal cases PSA ranges from $0-4 \mathrm{ng} / \mathrm{ml}$. Values between $4-10 \mathrm{ng} / \mathrm{ml}$ are seen in cases of $B P H$ and above levels are seen in prostatic cancer. Normal serum PAP ranges from 0-5 K.A units/dl. Elevated levels can be seen in benign conditions like BPH and also in malignant conditions like prostate cancer with and without metastasis. Total PSA levels were estimated by ELISA and serum PAP levels were estimated by K.A method. Results: In our present study, significant elevation $(p<0.001)$ of PSA was observed in malignant tumours with >20ng/dl and in BPH around $10 \mathrm{ng} / \mathrm{ml}$. Serum PAP levels were elevated in cases of BPH and prostatic cancer. Conclusion: Significant elevation of total PSA in BPH cases and cancer of the prostate with and without metastasis.
\end{abstract}

Key words: PSA, Serum PAP, BPH, Prostatic cancer.

\section{Introduction}

Carcinoma of the prostate is the most common malignant tumour in men over the age of 65yrs[3]. Prostate cancer is the second most frequent cause of cancer in males after the lung cancer in the developed regions[1]. In India it is the $4^{\text {th }}$ most leading cancer of death[4].

Prostate cancer has become a major public health problem worldwide[13]. In India the incidence of prostate cancer is higher in Bangalore, Chennai, Delhi and Mumbai than other areas[1]. More than 95\% cancers of prostate are adeno carcinomas and $<5 \%$ include the other ones.

The prostate gland is an accessory gland of the male reproductive system[11]. The gland lies in the lesser pelvis, below the neck of the urinary bladder; behind the lower part of the pubic symphysis. It has a purely sexual function. Many carcinomas are from the peripheral zone of the gland where as non-malignant or benign growths are from transitional zone.

Several aetiological factors are known to be associated with prostate cancer. The environmental or life style factors may play an important role in either initiating or promoting prostate cancer[14] Risk factors of prostate cancer are age above 60yrs[2], positive family history[3], high dietary fat intake[2], previous gonococcal infections[5], use of androgens[6] etc.

Prostate cancer spread to distant parts by three modes Local spread, Lymphatic spread, and Blood spread[4]

Early stages of prostate cancer is asymptomatic, Only advanced cases give rise to symptoms. But even advanced cases may be asymptomatic for sometime[3]. Symptoms of the prostate cancer are mainly due to obstruction to the flow of urine, infection or both [5] They are hesitancy,straining to initiate, terminal dribbling. frequency with nocturia, urinary retention.

Rectal examination is the most important step in the diagnosis of cancer of the prostate. Hard cancerous nodules, irregular induration, obliteration of the median sulcus, and non-mobility of the rectal mucosa over the enlarged prostate suggest carcinoma of the prostate[4]

Needle biopsy through the perineum, or transrectally, is a very useful procedure for establishing the diagnosis of cancer[5]

Trans-rectal ultrasonography (TRUS) is now frequently used procedure to detect early prostate cancer and also for staging of cancer. It also shows the urethral obstruction which causes hydronephrosis or hydroureter[4]

\section{Biochemical Aspects Of Psa \& Pap}

1.Prostate specific antigen (PSA) (EC 3.4.21.77)

PSA is produced by both normal prostatic tissue and by hyperplastic and neoplastic prostatic tissue . However, cancerous prostatic tissue produces about 10 times more PSA than normal tissue [8].

There are three major proteins secreted by the prostate gland[7] . They are :

1. Prostate Specific Antigen (PSA). It is also called seminin, or $\gamma$ - seminoprotein or seminogelase.

2. Prostatic Acid Phophatase (PAP). 
3. Prostate Specific Protein -94 (PSP-94). It is also termed as $\beta$-inhibin or $\beta$-micro seminoprotein or $\beta$ MSP.

PSA is one of few organ specific tumour markers. In 1979 \& 1983 Wang and colleagues reported human PSA is a very important makrer of the prostate and prostate pathology[7]. PSA is produced by both normal prostatic tissue and by hyperplastic and neoplastic prostatic tissue[8].

The normal value of PSA is $0-4 \mathrm{ng} / \mathrm{ml}$. This level is raised upto $10 \mathrm{ng} / \mathrm{ml}$ with BPH. Men with locally confirmed prostate cancer have serum levels $>10 \mathrm{ng} / \mathrm{ml}[4]$. Patients with organ confined disease seldom have a PSA level $>50 \mu \mathrm{g} / \mathrm{Lt}$, suggesting that patients with these elevated levels are most likely to have extracapsular tumour extension[8].

2.Prostatic Acid Phosphatase (PAP) (EC 3.1.3.2)

The acid phosphatase include all phosphatases that hydrolyze phosphate esters with an optimal $\mathrm{pH}$ of less than 7.0. Although acid phosphatase is produced primarily by the prostate gland, it is also found in erythrocytes, platelets, leukocytes, bone marrow, liver, spleen, kidney, and intestine[8].

PAP was first used as tumour marker in 1938 by Gutman and associates[8]. PAP is produced by the lysosomal fraction of epithelial prostate cells. Normal PAP ranges from 0 to $5 \mathrm{~K} \mathrm{~A}$ Units / dl. Prostate and osteoclasts are rich source of acid phosphatase[10]. PAP with an optimal pH of 5 to 6 is very labile at a pH of greater than 7.0 and a temperature greater than $37^{\circ} \mathrm{C}$.

Elevations of the enzymatic activity of PAP are found in the sera of about $60 \%$ of men with prostatic cancer with metastases[8]. However, when the carcinoma remains localized in the prostate gland, normal or only slightly raised levels of enzyme activity are found[8].

After surgery or anti androgen therapy the levels slowly approach normal, with a subsequent rise if the treatment is unsuccessful[8]. The levels of this enzyme are also elevated in patients with BPH [4].

Elevated serum PAP may be seen in malignant conditions such as osteogenic sarcoma, multiple myeloma and bone metastases of other cancers. It may also be elevated in some benign conditions such as BPH, osteoporosis, and hyperparathyroidism. Eelevated levels in a patient with metastases quickly return to normal once the disease is controlled by appropriate treatment[8].

\section{Materials And Methods}

For the present study, samples were collected from patients attending to Urology OPD of Government General Hospital, Guntur. 50 patients were studied against 20 control patients above 50 years. The diagnosis of prostate cancer was made according to the clinical symptoms, histopathological examination, ultrasonography and radiological examination.

The patients were divided, for convenience of study, into three groups.

Group I : $\quad$ Patients with benign prostatic hyperplasia.

Group II : $\quad$ Patients with prostate cancer without metastases.

Group III : $\quad$ Patients with prostate cancer with metastases.

The control group comprised of 20 healthy adult males above 50 years.

\subsection{Collection of samples}

Whole blood was collected from patients as well as from controls. Clear serum without haemolysis is separated into clean bottles and labeled.

\subsection{Precautions}

1. Anticoagulants should not be added to the blood [12].

2. Specimen should be free from haemolysis[12]

3. Enzymes should be assayed without storage[12].

4. Acid phosphatase is very unstable[12] and heat labile and becomes inactivited if the serum kept at $37^{\circ} \mathrm{C}$ for an hour[10] . It will deteriorate even if refrigerated unless the $\mathrm{pH}$ of the serum is adjusted to 6.0 or below with citric acid[12] .

5. For PSA estimation serum should be collected before doing procedures like perineal biopsy, transurethral resection and digital rectal examination[8].

6. Serum should be collected from ambulatory and non-hospitalised patients because after patient has been hospitalized for $24 \mathrm{hrs}$, serum PSA is decreased by $18 \%$ [8].

7. Owing to the 2 to 3 days half life of PSA, 2 to 3 weeks may be necessary for the serum PSA level to return to baseline after procedure[8].

\subsection{Serum prostate specific antigen}

Total PSA in serum was measured by enzyme immunoassay for the quantitative determination in prostate cancer patients. 


\subsubsection{Principle of the test[15]:}

The PSA EIA is based on the principle of a solid phase enzyme linked immunosorbent assay. The assay system utilizes a rabbit anti-PSA antibody directed against intact PSA for solid phase immobilization (on the micro titer wells). A monoclonal anti-PSA antibody conjugated to horseradish peroxidase (HRP) is in the antibody -enzyme conjugate solution. The test sample is allowed to react first with the immobilized rabbit antibody at room temperature for $60 \mathrm{~min}$. The wells are washed to remove any unbound antigen. The monoclonal anti-PSA-HRP conjugate is then reacted with the immobilized antigen for 60min at room temperature resulting in the PSA molecule being sandwiched between the solid phase and enzyme-linked antibodies. The wells are washed with water to remove unbound-labeled antibodies. A solution of TMB (tetra methyl benzedene $\mathrm{Hcl}$ ) reagent is added and incubated at room temperature for $20 \mathrm{~min}$, resulting in the development of a blue color. The color development is stopped with the addition of $1 \mathrm{~N} \mathrm{Hcl} \mathrm{changing} \mathrm{the} \mathrm{color}$ to yellow. The concentration of PSA is directly proportional to the color intensity of the sample. Absorbance is measured spectrophotometrically at $450 \mathrm{~nm}$.

\subsubsection{Expected values:}

Healthy males are expected to have PSA values below $4 \mathrm{ng} / \mathrm{ml}$.

\subsection{Serum acid phosphatase}

Serum acid phosphatase activity was measured by King-Armstrong method which is modified by substituting the acid buffer. The reaction is carried out at $\mathrm{pH} 4.9[10]$.

\subsubsection{Principle}

In the presence of oxidizing agent, 4-amino-antipyrine gives a red or purple color with compounds containing a phenolic group. This reaction is used to determine the phenol produced by the action of phosphatase on disodium phenyl phosphate. Colour development is rapid and stable for at least an hour, out of a bright light. Read at 520nm[10].

\section{Results}

\section{Comparative Study of BPH cases with controls}

\begin{tabular}{|c|c|c|c|}
\hline Parameters & Controls & BPH & Significance \\
\hline Prostate Specific antigen & $3.25+1.09$ & $8.09 \pm 1.68$ & $\mathrm{P}<0.001$ \\
\hline Serum Acid Phosphatase & $3.96+1.06$ & $8.6+3.15$ & $\mathrm{P}<0.01$ \\
\hline
\end{tabular}

Comparative Study of Prostate cancer without metastases with controls

\begin{tabular}{|l|l|l|l|}
\hline Parameters & Controls & $\begin{array}{c}\text { Prostate cancer without } \\
\text { metastases }\end{array}$ & Significance \\
\hline Prostate Specific antigen & $3.25 \pm 1.09$ & $29.00 \pm 8.25$ & $\mathrm{P}$ \\
\hline Serum Acid Phosphatase & $3.96 \pm 0.001$ & $\mathrm{P}<0.001$ \\
\hline
\end{tabular}

Comparative study of prostate cancer with metastases with controls

\begin{tabular}{|l|l|l|l|}
\hline Parameters & Controls & Prostate cancer with metastases & Significance \\
\hline Prostate Specific antigen & $3.25 \pm 1.09$ & $122.07+66.96$ & $\mathrm{P}<0.001$ \\
\hline Serum Acid Phosphatase & $3.96 \pm 1.06$ & $23.45 \pm 4.42$ & $\mathrm{P}<0.001$
\end{tabular}

\subsection{Prostate Specific Antigen}

\section{Discussion}

PSA is an extremely useful tumor marker for prostate cancer. In normal cases, the range is 0.4 $\mathrm{ng} / \mathrm{ml}$, values between 4 and $10 \mathrm{ng} / \mathrm{ml}$ may be seen in case of BPH value above $10 \mathrm{ng} / \mathrm{ml}$ may signify presence of cancer of the prostrate.

In our present study twenty normal people were choosen and found that the total PSA levels were in the range of $1-6 \mathrm{ng} / \mathrm{ml}$ with a mean value of 3.25 and with S.D of \pm 1.09 .

A cut off level for PSA of $4 \mathrm{ng} / \mathrm{ml}$ is used for screening, it was observed that $65 \%$ of men with PSA levels higher than $4 \mathrm{ng} / \mathrm{ml}$ do not have prostate cancer and $20 \%$ of men with diagnosed prostate cancer have PSA values below $4 \mathrm{ng} / \mathrm{ml}$.

The PSA levels in BPH and early cancer prostate may be similar. The overlap of PSA values between early cancer and BPH is so extensive that selecting an optimum cut off value of PSA either 4 or $10 \mathrm{ng} / \mathrm{ml}$ is almost impossible.

BPH is seen in $75 \%$ of men above the age of 60 years[9]. In our present study 25 patients with clinically diagnosed BPH were choosen. The total PSA levels were in the range of 5.5 to $12 \mathrm{ng} / \mathrm{ml}$ with a mean value of 8.09 and with S.D of \pm 1.68 . 
Higher PSA levels are associated with advanced stage of cancer prostate. Patients with organ confined disease rarely have PSA level greater than $50 \mathrm{ng} / \mathrm{ml}$.

In our present study, 17 cases of cancer prostate without metastasis were choosen. The total PSA level were in the range of 12.3 to $48 \mathrm{ng} / \mathrm{ml}$ with a mean value of 29.00 and with S.D of \pm 8.25 .

The level of PSA is more useful in evaluating the presence of metastases. Patients with $<20 \mathrm{ng} / \mathrm{ml}$ have bone metastases. In our present study 10 cases of cancer prostate with metastases were choosen. The total PSA levels were in the range of 66.9 to $280 \mathrm{ng} / \mathrm{ml}$ with a mean value of 122.07 and with S.D of \pm 66.96 .

The greatest clinical use of PSA is the monitoring of treatment of cancer patients.

\subsection{Prostatic Acid Phosphatase (PAP)}

Determination of PAP is mainly useful to detect and stage of cancer prostate or monitor treatment of cancer prostate. Elevations of the prostatic acid phosphatase and thus of total PAP activity are found in sera of $60 \%$ of men with prostate cancer with metastases. The levels may rise 40 to 50 times of the upper limit of the reference value.

In our present study, twenty normal persons were choosen and serum total PAP levels were estimated. PAP levels were in the range of 2.5 to $6 \mathrm{KAU} / \mathrm{dl}$ with a mean value of 3.96 with S.D of \pm 1.06 . Twenty five patients with clinically diagnosed BPH were selected and PAP levels were in the range of $\overline{5}$ to 20 $\mathrm{KAU} / \mathrm{dl}$ with a mean value of 8.6 and S.D of \pm 5.02 , Ten cases of cancer prostate with metastases were taken and PAP levels were in the range of 18 to $32 \mathrm{KAU} / \mathrm{dl}$ with a mean value of 23.45 and with S.D of \pm 4.4 .

Thus, significant elevation of PAP levels were noted in case of cancer prostate with and without metastases.

\section{Conclusion}

Prostate specific antigen (PSA) is an extremely useful tumor marker for detection and monitor treatment of cancer of the prostate. Serum PSA levels also raised in BPH, prostatitis transurethral resection of the prostate and after ejaculation.

To increase the specificity to distinguish between BPH and cancer of the prostate determination of ratios of free / total PSA, complex / total PSA are useful. The percentage of free PSA is decreased in cancer of the prostate.

PSA levels are also useful to detect metastases in cancer prostate, recurrence after radical prostatectomy, or radiation therapy and to monitor antiandrogen therapy.

In our present study significant elevations of total PSA levels in patients suffering from BPH, cancer of the prostate with and without metastases were noted. PSA levels are useful to detect metastases in cancer prostate, recurrence after radical prostatectomy, or radiation therapy and to monitor anti androgen therapy.

Elevations ofPAP levels also noted in case of cancer of the prostate with and without metastases. The levels of total prostate specific antigen (PSA), Serum acid phosphatase (ACP) were with in normal range in all control persons.

\section{References}

[1]. K. Park: Text book of Preventive and Social Medicine $17^{\text {th }}$ Edition, P 285-294

[2]. Daniel Shoskes: Cancer of the prostate. Oxford Text book of Surgery. Edited by Peter J. Morris and Ronald A. Malt, Vol-2, P 15931601 .

[3]. Charles V.Mann:Bailey \& Love's Short Practice of Surgery, $22^{\text {nd }}$ edition, P 970-984.

[4] Somen Das: A concise textbook of surgery, $3^{\text {rd }}$ edition, P 1245-1253.

[5]. $\quad$ Donald R. Smith: General Urology $9^{\text {th }}$ Edition, P 290-297.

[6]. Robbin's Pathologic Basis of Disease $4^{\text {th }}$ Edition, p1112-1125.

[7]. Donald S.Coffey:The molecular Biology, Endocrinology, Physiology of Prostate and Seminal Vesicles: Campbell's Urology, Volume $-\mathrm{I}, 6^{\text {th }}$ Edition, P 254-256

[8]. Carl A. Burtis et al: Tietz textbook of Clinical Chemistry $3^{\text {rd }}$ Edition. P 657-666.

[9]. Robert K. Murray et al: Harper's Biochemistry $12^{\text {th }} \mathrm{Ed}$

[10]. Har old Varley: Practical Clinical Biochemistry $4^{\text {th }}$ Ed. P 297-299, 461-465.

[11]. B.D. Chaurasia's: Human Anatomy Vol.2, 2 ${ }^{\text {nd }}$ Edition, P 327-330.

[12]. Kenneth E. Blick: Principles of Clinical Chemistry P 452-465.

[13]. Ann. W. Hsing: A Glimpse into the future. Epidemiol Rev.Vol.23, No1, 2001.

[14]. Donald S. Coffey: New insights and methodologies are needed to solve the many epidemiologic Enigmas of prostate cancer. Epidemiol, Rev.Vol.23, No.1, 2001.

[15]. Literature provided along with PSA EIA Kit. 